\title{
Sublethal exposure to an emulsion based on Pogostemon cablin (Lamiaceae) essential oil impairs digestibility, feeding, fecundity, and mobility of the coffee berry borer, Hypothenemus hampei
}

Abraão Almeida Santos ( $\nabla$ abraaoufs@gmail.com )

University of Florida https://orcid.org/0000-0001-5284-3294

Cliver F. Farder-Gomes

Universidade Federal de Vicosa

Arthur V. Ribeiro

University of Minnesota Twin Cities Campus: University of Minnesota Twin Cities

Thiago L. Costa

Universidade Federal de Vicosa

Josélia Carvalho Oliveira França

Universidade Federal de Lavras

Leandro Bacci

Universidade Federal de Sergipe

Antônio Jacinto Demuner

Universidade Federal de Vicosa

José Eduardo Serrão

Universidade Federal de Vicosa

Marcelo Coutinho Picanço

Universidade Federal de Vicosa

Research Article

Keywords: Acute toxicity, Biorational insecticides, Microscale, Scolytinae, Sublethal effect

Posted Date: January 5th, 2022

DOI: https://doi.org/10.21203/rs.3.rs-1225862/v1

License: (c) (1) This work is licensed under a Creative Commons Attribution 4.0 International License.

Read Full License 


\section{Abstract}

The global search for eco-friendly and human-safe pesticides has intensified, and research on essential oils (EOs) has expanded due to their remarkable insecticidal activities and apparent human-safe. Despite this, most of the literature focuses on short-term and simplified efforts to understand lethal effects, with only a few comprehensive studies addressing sublethal exposures. To fill this shortcoming, we explore the lethal and sublethal effects of Pogostemon cablin (Lamiaceae) EO and an EO-based emulsion (18\%) using the coffee berry borer Hypothenemus hampei Ferrari (Coleoptera: Curculionidae: Scolytinae) as a model. First, we determine the toxicity of EO and EO-based emulsion using dose-mortality curves and lethal times. Second, we subjected adult females of $H$. hampei to sublethal doses to assess whether they affected their behavior, reproductive output, and histological features. Our findings reveal that patchoulol (43.05\%), a-Guaiene (16.06\%), and a-Bulnesene (13.69\%) were the main components of the EO. Furthermore, the EO and its emulsion had similar toxicity, with dose-mortality curves and lethal times overlapping $95 \%$ confidence intervals. We also observed that sublethal exposure of females of $H$. hampei reduces reproduction and feeding, increases walking activity, and causes histopathological changes in the midgut. This study advances the knowledge of sublethal effects of an eco-friendly substance on insects.

\section{Introduction}

Insecticide misuse in agriculture has been associated with food, water, and environmental contamination, increasing the search for safer substances in pest control, including environmentally friendly molecules that can be used without negatively affecting human and environmental health (Bolzonella et al. 2019). Essential oils (EOs) are a potential source for new eco-friendly insecticides (Regnault-Roger et al. 2012; Isman 2020) because they are byproducts of plants' secondary metabolites with biological effects. The studies on the insecticidal activity of EOs have increased because these substances have low environmental persistence and toxicity to non-target organisms (Regnault-Roger et al. 2012; Santos et al. 2018; Isman 2020). However, the insecticide activity of EOs may be reduced when released in the environment due to its rapid degradation, and emulsions containing EO are a strategy to overcome this drawback (Pavoni et al. 2020).

The advantages of EO-based emulsions for the development of eco-friendly insecticides include: (i) reduction in EO particle size; (ii) delayed release of active ingredients in the environment; and (iii) increased EO penetration in the insect body (Athanassiou et al. 2018; Pavoni et al. 2020). Nevertheless, plant-based insecticide, such as EO, have been evaluated mainly regarding their acute toxicities, while sublethal effects are often overlooked (Turchen et al. 2020).

The coffee berry borer (CBB), Hypothenemus hampei Ferrari (Coleoptera: Curculionidae: Scolytinae), is the leading pest of coffee crops worldwide, causing economic losses of up to US\$500 million annually (Vega et al. 2002). Females bore the fruits and lay eggs in the endosperm, where newly hatched larvae and adults feed. CBB causes economic damage by reducing coffee grains' quality and market value 
(Infante 2018). Also, immatures and adults can feed on a single fruit simultaneously because of the fast development of CBB (estimated cohort generation time of 45 days) aligned with the high longevity of adults (Baker et al. 1992).

For many years, conventional insecticides, such as endosulfan, were at the forefront of CBB management (Vega et al. 2015). Despite its efficacy, endosulfan has been banned from 70 countries, including Brazil, one of the primary coffee producers worldwide, because it is a persistent organic pollutant that causes human and environmental hazards (Vega et al. 2015; Menezes et al. 2017). The limited options for the management of CBB led to the search for alternative molecules, but mainly conventional synthetic insecticides have been investigated (e.g., Plata-Rueda et al. 2019).

The insecticide effect of EOs against CBB has been documented (e.g., Reyes et al. 2019). However, the development of emulsions containing these oils and knowledge on their sublethal effects is lacking. Therefore, we sought in this study to test the lethal and sublethal effects of Pogostemon cablin (Benth.) Blanco (Lamiaceae) and its emulsion against CBB. The EO of $P$. cablin has been previously reported showing insecticidal activity (Albuquerque et al. 2013; Rocha et al. 2018), but its effect on CBB is still unknown. Thus, we addressed the question: Can a emulsion of $P$. cablin $\mathrm{EO}$ achieve lethal and sublethal toxicity similar to that of the pure oil on CBB?

\section{Material And Methods}

\section{Insects and essential oil}

We obtained adult females of $H$. hampei from infested coffee berries (Coffea arabica L. cv. Catuaí) collected in an organic field $\left(-20.739994^{\circ},-42.847968^{\circ}\right)$, Viçosa, state of Minas Gerais, Brazil. The females were kept in the dark at $27 \pm 0.5^{\circ} \mathrm{C}, 65 \pm 10 \%$ relative humidity to produce one generation (F1). The $\mathrm{F} 1$ females were removed from the fruits $24 \mathrm{~h}$ before the bioassays. The EO of $P$. cablin (98\% purity) was purchased from Empório Laszlo Corp. (Belo Horizonte, State of Minas Gerais, Brazil).

\section{Emulsion preparation}

The emulsion was obtained with the magnetic stirring method (Corning PC-420D). The emulsion was composed of 36\% Tween 80 (Dinâmica Química Contemporânea Ltda., São Paulo, Brazil; surfactant), $36 \%$ ethanol (Neon Comercial Ltda., São Paulo, Brazil, 95\% PA; co-surfactant), $18 \%$ EO of P. cablin (oil phase), and 10\% ultra-pure water (aqueous phase) following Liu et al. (2011), which provide suitable oil particle size stability (Liu et al. 2011; Rocha et al. 2018). The emulsion was kept at $25^{\circ} \mathrm{C}$ in darkness for $24 \mathrm{~h}$ for complete homogenization in amber vials and used 15 days after its preparation in the bioassays.

\section{Essential oil and emulsion: chemical and physical analyses}

Fifteen days after preparation, the EO chemical composition and EO-based emulsion physical aspects were determined. Quantitative analysis of EO components was done in a Shimadzu GCMS-QP5050A apparatus fitted with a capillary DB- 5 column $(30 \mathrm{~m} \times 0.25 \mathrm{~mm}$, with $0.25 \mu \mathrm{m}$ film thickness) coupled 
with a flame ionization detector, using helium as the carrier gas (flow rate of $1.8 \mathrm{~mL} \mathrm{~min}-1$ ) and injector temperature of $220^{\circ} \mathrm{C}$. The initial column temperature was $40^{\circ} \mathrm{C}$. Isotherm was kept for $2 \mathrm{~min}$, and then the temperature was increased to $240^{\circ} \mathrm{C}$ at a rate of $3^{\circ} \mathrm{C} \mathrm{min}^{-1}$. This system was maintained for $15 \mathrm{~min}$ before injecting the sample $(1.0 \mu \mathrm{L})$ in a split ratio of 1:20 and a column pressure of $100 \mathrm{kPa}$. Component concentrations were calculated as the percentage of the corresponding peak area to the total area of all peaks. The qualitative analysis was done in a Shimadzu GC17A apparatus fitted with a capillary DB-5 column (30 m × $0.25 \mathrm{~mm}$, with $0.25 \mu \mathrm{m}$ film thickness) using electron impact ionization $(70 \mathrm{eV})$. Injector temperature, isotherm, column pressure, and heating rate were similar to those mentioned above. Thereafter, components were identified by comparing their retention times to a series of alkanes (C9 C27) and their mass spectra to the library database of Wiley and Nist $(05,08$, and 11$)$.

The physical parameters of the emulsion related to conductivity, microparticle size, $\mathrm{pH}$, and zeta potential were characterized. Zeta potential is related to the repulsive forces existing between the particles, where an increase in these forces provides more stability and avoids the agglomeration of EO particles within the emulsion. Thereby, values higher than $+25 \mathrm{mV}$ or lower than $-25 \mathrm{mV}$ indicate high degrees of strength (Shi et al. 2017; Hashem et al. 2018). For pH values, those lower than 4 or higher than 7.5 indicate that the dispersion would be expected to be stable (Oliveira et al. 2017). Furthermore, conductivity indicates percolation transition in water/oil rates (Liu et al. 2011).

The size of emulsion samples was obtained using an Olympus BX-53 light microscope, coupled with an Olympus DP 73 digital camera (Olympus Optical Corp., Tokyo, Japan). The computer program ImageJ was used to measure the diameter of the particles for 250 observations (National Institutes of Health, $\mathrm{NIH}$, Maryland, USA). Zeta potential and conductivity were analyzed using a ZetaSizer Nano ZS90 (Malvern Instruments Inc., Worcestershire, UK) and pH using a bench pHmeter (Digimed DM 20) in triplicate. Previously, samples were diluted with 1:100 (v:v) ultra-pure water, and evaluations were performed at $25^{\circ} \mathrm{C}$ in triplicate (Oliveira et al. 2017).

\section{Bioassays}

All experiments were performed in a completely randomized design using newly emerged adult females and treatments involving P. cablin EO, the EO-based emulsion, and acetone (control).

Dose-mortality bioassay

Serial dilutions in acetone of $P$. cablin EO $(5,10,30,40,50$, and $60 \mu \mathrm{g}$ of EO per $\mathrm{mg}$ of insect) and the EObased emulsion $(10,20,30,50$, and $60 \mu \mathrm{g}$ of emulsion per $\mathrm{mg}$ of insect) were prepared to estimate lethal doses through dose-mortality curves (i.e., toxicity) for females with similar weight $(0.45 \pm 0.02 \mathrm{mg})$.

Four replicates were used per tested dose, with each replicate consisting of 10 females caged in a Petri dish (7.5 cm diameter $x 2 \mathrm{~cm}$ height) containing $1.5 \mathrm{~g}$ of coffee berry for feeding. The topical application consisted of $0.5 \mu \mathrm{L}$ of the treatment solution applied on the thorax of each female with a Hamilton microsyringe $(10 \mu \mathrm{L})$. A previous bioassay indicated that neither acetone nor the mixture used in the emulsion without the EO affected the survival of the insects (ANOVA: $F=0.16 ; d f=2,9 ; P=0.85$, Fig. S1, 
supplementary information). After the topical application, the insects were kept in the dark at $27 \pm 0.5^{\circ} \mathrm{C}$, $65 \pm 10 \%$ relative humidity, and the number of dead insects was counted for $72 \mathrm{~h}$.

Time-mortality bioassay

The calculated $\mathrm{LD}_{90}$ for the $\mathrm{EO}$ and the EO-based emulsion and control were topically applied as aforementioned with five replicates per treatment and 10 females per replicate $(n=50$ females per treatment; 150 in total). The number of live insects was registered every $10 \mathrm{~min}$ up to $4 \mathrm{~h}$, every $2 \mathrm{~h}$ up to $12 \mathrm{~h}$, and every $12 \mathrm{~h}$ up to $72 \mathrm{~h}$.

\section{Fecundity}

The calculated $\mathrm{LD}_{25}$ for the EO, EO-based emulsion and acetone control were topically applied as aforementioned. Twenty replicates, each of which was one insect, were used for each treatment $(n=20$ females per treatment; 60 in total). Each female was supplied with a coffee berry for the oviposition site three hours after exposure to the chemicals. The coffee berries were washed with $1.0 \%$ sodium hypochlorite, distilled water, and air-dried for two days before being exposed to the treated females. The potential bias from fruit size was reduced using berries with similar sizes [diameter (ANOVA; $F=0.85 ; \mathrm{df}=$ $2,57 ; P=0.43$ ) and height (ANOVA; $F=0.46 ; d f=2,57 ; P=0.63)$. Fruits were kept separately in individual vials ( $5.0 \mathrm{~cm}$ diameter $\times 2.5 \mathrm{~cm}$ height) at $27 \pm 0.5^{\circ} \mathrm{C}$ and $65 \pm 10 \%$ relative humidity in the dark. The coffee berries were mechanically opened after 30 days, and the number of $H$. hampei larvae counted.

\section{Feeding}

We investigate if feeding by $H$. hampei adult females treated with the $\mathrm{LD}_{25}$ of either $P$. cablin $\mathrm{EO}$ or the EO-based emulsion reduces the mass of coffee berries. Ten replicates, each one with one berry and five females, were placed in a Petri dish $(7.5 \mathrm{~cm}$ diameter $\times 2 \mathrm{~cm}$ height; $\mathrm{n}=50$ females per treatment; 150 in total). The coffee berries were weighed on an analytical balance (Genaka, AG200) before and after $72 \mathrm{~h}$ of exposure to the females. Another set of 10 replicates containing only coffee berries was used to correct the mass in the treatments and control to reduce the bias due to water loss. The Petri dishes were kept in a desiccator at $27 \pm 0.5^{\circ} \mathrm{C}$ and $65 \pm 10 \%$ relative humidity in the dark to reduce the interference of relative humidity on grain weight. The temperature $\left(25.80 \pm 0.6^{\circ} \mathrm{C}\right)$ and relative humidity $(54.20 \pm 5.80 \%)$ inside the desiccator were monitored using a digital thermohygrometer (Kasvi K295070H). The coffee berries used had similar initial weight (ANOVA: $F=0.14 ; \mathrm{df}=3,36 ; \mathrm{P}=0.94$ ). Results were calculated as percent berry weight loss (BWL) using the formula:

\section{BWL(\%) $=\{[$ (initial mass - final mass $) \div$ final mass $] * 100\}$.}

Mobility

The H. hampei females were exposed to the $\mathrm{LD}_{25}$ of $P$. cablin EO, EO-based emulsion, and acetone as the control to evaluate insect mobility. Fifteen replicates were used per treatment, in which each replicate 
consisted of one female ( $\mathrm{n}=15$ females per treatment; 45 in total) in a Petri dish $(7.5 \mathrm{~cm}$ diameter $\times 2 \mathrm{~cm}$ height). The insects were kept at $27 \pm 0.5^{\circ} \mathrm{C}$ and $65 \pm 10 \%$ relative humidity in darkness for $72 \mathrm{~h}$. Each female was kept at room temperature for one hour for acclimatization, transferred to a Petri dish, and recorded for 10 min using an automated video tracking system equipped with a charge-coupled device camera (ViewPoint Life Sciences, Montreal, Canada) for the calculation of the displacement $(\mathrm{cm})$ and walking velocity $(\mathrm{cm} / \mathrm{s})$.

\section{Histopathological analysis}

Adults of $H$. hampei from the control $(n=5)$, and those topically exposed for $72 \mathrm{~h}$ to the $\mathrm{LD}_{25}$ of either the EO $(n=5)$ or the EO-based emulsion $(n=5)$ were cryo-anesthetized at $4{ }^{\circ} \mathrm{C}$ for 5 minutes, dissected in insect saline solution ( $0.1 \mathrm{M} \mathrm{NaCl}, 0.1 \mathrm{M} \mathrm{KH}_{2} \mathrm{PO}_{4}, 0.1 \mathrm{M} \mathrm{Na}_{2} \mathrm{HPO}_{4}$ ), and the midgut, brain, and ovaries were transferred to Zamboni's fixative solution for $24 \mathrm{~h}$ at $5^{\circ} \mathrm{C}$. Subsequently, samples were dehydrated in a graded ethanol series $(70,80,90$, and 95\%) and embedded in historesin Leica (Leica Biosystems Nussloch $\mathrm{GmbH}$, Heildelberger, Germany). Sections with $3 \mu \mathrm{m}$ thickness were stained with hematoxylin and eosin and analyzed using an Olympus BX-53 light microscope, coupled with an Olympus DP 73 digital camera (Olympus Optical Corp., Tokyo, Japan).

\section{Statistical analyses}

All statistical analyses were performed using the R software (R Core Team 2021) and packages described below for analyses and the R software [with the package ggplot2 (Wickham 2016)] and Corel Painter (Essential 7, Ottawa, ON, Canada) for graphics design.

The lethal doses of the $P$. cablin EO and the EO-based emulsion to H. hampei were determined with doseresponse curves using PROBIT analysis, available in the ecotox package (Hlina 2020). Models with a probability of acceptance of the null hypothesis $(P>0.05)$ were accepted by the chi-square goodness-offit test $\left(\chi^{2}\right)$ and estimated 95\% confidence intervals (CI 95\%).

The time mortality was estimated using Kaplan-Meier estimators in the package survival (Therneau 2021). Subsequently, the curves and $\mathrm{LT}_{50} \mathrm{~S}$ (including $\mathrm{Cl} 95 \%$ ) from treatments were compared using the Log-rank test with Bonferroni correction to avoid false-positive results.

The fecundity and feeding data were fitted in generalized linear models (GLM) using the package Ime4 (Bates et al. 2015), setting treatment as the fixed effect and error distribution accordingly. Data from the bioassays for the number of larvae were initially investigated under a Poisson error distribution but subsequently refitted using Quasi-Poisson (link function = log) as overdispersion was detected. Similarly, we initially used binomial error distribution but updated it to Quasi-Binomial (link function $=$ logit) due to overdispersion for berry mass loss data. Models validity and quality were checked using the package performance (Lüdecke et al. 2021). When data showed the significance of treatments, means were compared by multiple pairwise comparisons using least-square means at $\mathrm{a}=0.05$ (package emmeans) (Lenth 2020). 
Mobility data were submitted to analysis of variance (ANOVA). Normality of residuals and homogeneity of variance were checked by Shapiro-Wilk and Bartlett's test, respectively, and data transformation was unnecessary. When data showed the significance of treatments, means were compared by Tukey's test ( $\mathrm{a}$ $=5 \%$ ).

\section{Results}

\section{Chemical composition and physical parameters}

We identified and quantified 12 compounds in the $P$. cablin EO with similar amounts from nonoxygenated and oxygenated terpenes (Table 1). Patchoulol (43.05\%), a-Guaiene (16.06\%), and aBulnesene (13.69\%) were the more abundant compounds.

Table 1

Chemical composition of the essential oil of Pogostemon cablin. $\mathrm{RI}=$ retention index.

\begin{tabular}{|lll|}
\hline $\mathbf{R I}$ & Compound & Concentration (\%) \\
\hline 1379 & $\beta$-Patchoulene & 1.36 \\
\hline 1389 & $\beta$-Elemene & 0.69 \\
\hline 1444 & Seychellene & 0.65 \\
\hline 1417 & E-Caryophyllene & 2.19 \\
\hline 1437 & a-Guaiene & 16.06 \\
\hline 1454 & a-Patchoulene & 5.54 \\
\hline 1473 & Y-Gurjunene & 2.37 \\
\hline 1467 & $\beta$-Caryophyllene & 0.20 \\
\hline 1492 & Eremophilene & 0.64 \\
\hline 1509 & a-Bulnesene & 13.69 \\
\hline 1582 & Caryophyllene oxide & 1.16 \\
\hline 1656 & Patchoulol & 43.45 \\
\hline Non-oxygenated sesquiterpenes (\%) & 43.39 \\
\hline Oxygenated sesquiterpenes (\%) & 44.61 \\
\hline Total detected (\%) & 88.00 \\
\hline
\end{tabular}

The EO-based emulsion obtained had a microparticle size of $3.73 \pm 3.70 \mu \mathrm{m}$ (mean \pm SD), with suitable stability as indicated by conductivity $(0.0472 \pm 0.0353 \mathrm{mS} / \mathrm{cm}), \mathrm{pH}(7.68 \pm 0.35)$, and zeta potential (- 


\section{Dose-mortality}

The estimated dose-response curves for the P. cablin EO $\left(X^{2}=7.35 ; \mathrm{df}=5 ; \mathrm{P}=0.20\right)$ and the EO-based emulsion $\left(\chi^{2}=2.66 ; \mathrm{df}=3 ; \mathrm{P}=0.45\right)$ had similar toxicity to $H$. hampei based on overlapping $95 \%$ confidence intervals (Fig. 2). The $L_{50}$ and $L_{90}$ for the EO were 19.20 (14.50-24.50) and 141.00 (85.00318.00) $\mu \mathrm{g}$ per $\mathrm{mg}$ of insect ${ }^{-1}$, respectively, whereas for EO-based emulsion were 28.60 (23.60-34.40) and 96.90 (70.60-168.0) $\mu \mathrm{g}$ per $\mathrm{mg}$ of insect $^{-1}$, respectively (Fig. 2).

\section{Time-Mortality}

When exposed to the $\mathrm{LD}_{90}$ from both treatments, survival of $H$. hampei female decreased according to time $\left(X^{2}=103, d f=2 ; P<0.0001 ;\right.$ Fig. S2, supplementary information), with the highest decrease during the first two hours after exposure. The $\mathrm{LT}_{50}$ for $H$. hampei female was similar between the EO $(10.05$, 10.00-20.00 $\mathrm{min}$ ) and the EO-based emulsion (10.00, 10.00-20.00 min) (Fig. 3).

\section{Fecundity}

The number of larvae produced by treated females decreased after exposure to EO of $P$. cablin and its EObased emulsion (GLM Quasi-Poisson distribution; $F=4.73, \mathrm{df}=2,57 ; \mathrm{P}=0.01$ ) but with a similar number

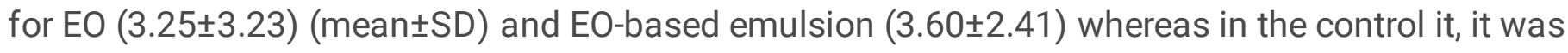
$6.00 \pm 2.41$ (Fig. 4).

\section{Feeding}

The mass of coffee berries consumed by $H$. hampei female decreased in those treated with $P$. cablin EO and its EO-based emulsion (GLM Quasi-Binomial distribution: $F=8.74, \mathrm{df}=2,27 ; \mathrm{P}=0.001$ ) from $2.23 \pm 1.03 \%$ (mean $\pm S D$ ) in the control, $1.22 \pm 0.41$ and $1.02 \pm 0.56 \%$ for the $E O$ and its emulsion, respectively (Fig. 5).

\section{Mobility}

The displacement was higher (ANOVA: $\mathrm{F}=14.23, \mathrm{df}=2,42 ; \mathrm{P}<0.0001$ ) for $\mathrm{H}$. hampei females treated with the $P$. cablin EO $(157.78 \pm 21.29 \mathrm{~cm})($ mean $\pm S D)$ and its emulsion $(148.39 \pm 19.88 \mathrm{~cm})$ than in the control insects $(124.07 \pm 10.35 \mathrm{~cm}$ ) (Fig. $6 \mathrm{a}$ ). The walking speed was higher (ANOVA: $\mathrm{F}=21.21, \mathrm{df}=2,42$; $\mathrm{P}<0.0001)$ for females treated with the EO $(0.45 \pm 0.03 \mathrm{~cm} / \mathrm{s})$, whereas for those treated with the EObased emulsion $(0.39 \pm 0.02 \mathrm{~cm} / \mathrm{s})$ were similar to the control $(0.38 \pm 0.01 \mathrm{~cm} / \mathrm{s})($ Fig. $6 \mathrm{~b})$.

\section{Histopathology}


The midgut epithelium of $H$. hampei had a single-layered epithelium with digestive cells showing homogeneous cytoplasm and a spherical nucleus with the predominance of decondensed chromatin (Fig. 7A). The apical surface had a well-developed brush border (Fig. 7B). After 72h of exposure to the EO, the midgut epithelium showed histopathological features, including irregular epithelium architecture, disorganization of brush border, cytoplasm vacuolization, and release of cell fragments into the gut lumen (Fig. 7C-D). In the adults treated with EO-based emulsion, those histopathological features were more severe with irregular epithelium, high disorganization of brush border and cytoplasm vacuolization, a nucleus with condensed chromatin, and release of cell fragments into the gut lumen (Fig. 7E-F).

In the brain and ovaries of $H$. hampei exposed insects, there was no damage compared with control. The brain had the neuropil region of the mushroom bodies and antennal lobe with a homogeneous aspect, and Kenyon cells had spherical nuclei with decondensed chromatin (Fig. 8A, C, and E). The insect ovarioles presented a well-developed tropharium region, oocyte with a prominent germinal vesicle (oocyte nucleus), surrounded by a layer of follicular cells, and a peritoneal sheath coating the entire ovariole (Fig. 8B, D, and F).

\section{Discussion}

The increasing concerns with human and environmental safety expedite progress towards adopting alternative substances in opposition to conventional synthetic pesticides to manage insect pests. However, research on formulations conferring higher stability for applications and the potential sublethal effects of new molecules is still needed. This study demonstrated that a emulsion containing $18 \%$ of $P$. cablin EO has similar acute toxicity and sublethal effects as its EO against the CBB, H. hampei. These findings contribute to the development and improvement of eco-friendly molecules and the advancement of the knowledge about plant-based insecticides and their lethal and sublethal effects, including histopathological aspects, thus helping to fill this current gap.

EO-based emulsions have been developed to overcome EO's rapid degradation and particle size, resulting in similar or higher insecticidal activity than its pure form. The estimated lethal doses obtained here are equivalent between $P$. cablin EO and its emulsion, indicating the potential of the emulsion for the control of $H$. hampei. Thus, we hypothesize that the main reasons for such success are: i) a reduction in the EO microparticle size associated with suitable conductivity, $\mathrm{pH}$, and zeta potential (i.e., greater particle repulsion), which can increase the efficiency and uniformity of a substance deposition on a surface; and ii) slower release of active ingredient resulting in prolonged insecticidal activity, which has been found for other EOs (González et al. 2015; Oliveira et al. 2017; Rocha et al. 2018). In the P. cablin EO evaluated here, patchoulol is the most abundant component and claimed to be responsible for this oil's insecticidal activity (Albuquerque et al. 2013; van Beek and Joulain 2018). So, it is reasonable to assume that this main compound was kept under a suitable stable system with nominal particle size in the emulsion, contributing to acute toxicity similar to that of the pure essential oil, as found in previous studies for leafcutting ants (Rocha et al. 2018). 
Noteworthy, the insecticidal effect of an EO is not uniquely related to the major compounds because synergistic, additive, or antagonistic interactions among components have been reported (Tak and Isman 2015; Tak et al. 2016; Melo et al. 2020). Those interactions among EO components may cause rapid mortality, which occurred with the P. cablin EO as indicated by the short lethal time. This fast mortality may be attributed to some mechanisms, including the interference in calcium channels and the inhibition of octopamine and acetylcholinesterase as reported for EOs of other Lamiaceae species (Rattan 2010; Park et al. 2016). Interestingly, the emulsion has a lethal time similar to that of the EO despite its lower EO content ( $18 \%$ of EO), which may be due to the (co) surfactants' proprieties that increase the penetration of the insect cuticle by EOs (Kogan and Garti 2006; Hashem et al. 2018).

Sublethal effects of the P. cablin EO and the EO-based emulsion to H. hampei include the impairment of reproduction and feeding with the low number of larvae produced and a decrease in the mass of coffee berries consumed by treated females. The increase in EO bioavailability through formulations is known to cause extensive damage to insect organs, impairing processes such as feeding (Hashem et al. 2018; Shahzad and Manzoor 2021). The histopathological changes found in the midgut of $H$. hampei treated with EO or EO-based emulsion included a disorganization of the brush border, cytoplasm vacuolization, and cell fragmentation, which are features of cell degeneration and indicate side effects of the treatments in this organ. Considering that brush border enhances the cell surface for the transport of substances (Serrão and Cruz-Landim, 1996; Terra et al., 2006), the damage in these structures may impair the digestion efficiency of $H$. hampei. Thus, the impairment of CBB reproduction (i.e., reduced number of larvae produced) may be due to an indirect effect of lower feeding and absorption.

After EO and EO-based emulsion exposure, the vacuolization in the digestive cells suggests possible autophagic cell death, which may impair cell survival (Santos Junior et al. 2020; Carneiro et al. 2020). Autophagy is primarily a survival mechanism that preserves the turnover of cell components (Noguchi et al. 2020). However, this process also kills cells after insecticide exposure, such as found for Anticarsia gemmatalis (Hübner) (Lepidoptera: Noctuidae) exposed to neem oil (Farder-Gomes et al. 2021c) and squamocin (Fiaz et al. 2018). Besides autophagy, the nuclear chromatin condensation indicates that EO and EO-based emulsion exposure may induce cell death by apoptosis in the midgut of $H$. hampei. Chromatin condensation is a common aspect of apoptotic cell death in organs undergoing degeneration, such as the midgut (da Silva Cruz et al. 2010; Farder-Gomes et al. 2021a) and brain (Farder-Gomes et al. 2021 b) after exposure to toxicants. In addition, the release of midgut cell fragments into the lumen may be related to the elimination of dead cells (da Silva Cruz et al. 2010; Farder-Gomes et al. 2021a) or renewal of cytoplasm content (Cruz-Landim et al. 1996) after the damage elicited by the EO and EObased emulsion.

Our results revealed that EO and the EO-based emulsion affect the mobility of $H$. hampei. Compounds that inhibit acetylcholinesterase cause hyperactivity in insects, leading to a higher displacement and irritability (Alzogaray et al. 1997; Cordeiro et al. 2010). EOs of Lamiaceae species exhibit a similar action due to oxygenated sesquiterpenes, which also act on a similar target site (Park et al. 2016), increasing insect displacement (Santos et al. 2018; Rocha et al. 2018; de Oliveira et al. 2019). In our study, 
oxygenated sesquiterpenes represented $44 \%$ of the EO composition and may be responsible for the higher displacement observed in the treated insects. Similar results have been reported in Atta sexdens (Linnaeus) (Hymenoptera: Formicidae) exposed to both P. cablin EO and its nanoformulation (Rocha et al. 2018).

This study shows lethal and sublethal effects of $P$. cablin EO and an EO-based emulsion (18\% of $P$. cablin EO) against the CBB, H. hampei adult female. Noteworthy, formulated EOs usually show toxicity and sublethal effects in a nano-scale $\left(10^{-9}\right)$ (González et al. 2015; Oliveira et al. 2017; Hashem et al. 2018; Rocha et al. 2018). Here, we found similar effects in a micro-scale $\left(10^{-6}\right)$, indicating that EO-based emulsions may have similar insecticidal activity as those of other commonly studied formulations (González et al. 2015; Oliveira et al. 2017; Hashem et al. 2018; Rocha et al. 2018). Overall, this study provides new insights for developing environmentally friendly molecules to manage insect pests that should be further evaluated under field conditions and for safety to non-target organisms.

\section{Declarations}

\section{Acknowledgments}

We would like to thank Dr. Clara Marques and Dr. Leonardo Turchen for their kindly assistance.

\section{Funding}

This study was supported by Conselho Nacional de Desenvolvimento Científico e Tecnológico - Brasil (CNPq), grant number 151765/2020-0.

\section{Supplementary information}

Fig. S1. Survival (mean \pm SD) of Hypothenemus hampei 72 hours after topical application of acetone, none, and surfactants (Ethanol + Tween $80+$ ultrapure water). All solvents did not affect the survival of females CBB (ANOVA: $F=0.16 ; d f=2,9 ; P=0.85$ ).

Fig. S2. Survival probability of Hypothenemus hampei after topical application of Pogostemon cablin essential oil (EO) and its emulsion (18\% of EO). Shaded areas represent $95 \%$ confidence intervals. Lower case letters indicate significant differences among treatments [Kaplan-Meier method, Log-Rank test ( $\chi 2$ $=103, \mathrm{df}=2 ; \mathrm{P}<0.0001)$ and Bonferroni correction].

\section{Author contribution}

AAS: Conceptualization, Data Curation, Methodology, Formal Analysis, Visualization, Writing - original draft, review \& editing, Funding Acquisition. CFF-G: Conceptualization, Data Curation, Methodology, Visualization, Writing - original draft. AVR: Writing - original draft, review \& editing. TLC: Data Curation, Methodology. JCOF: Data Curation, Methodology. LB: Writing - review \& editing. AJD: Data Curation, Methodology, Resources, Writing - review \& editing. JES: Conceptualization, Methodology, Resources, 
Supervision, Writing - review \& editing. MCP: Conceptualization, Funding Acquisition, Resources, Supervision, Project administration, Writing - review \& editing.

\section{Data availability}

The datasets used and/or analyzed during the current study are available from the corresponding author on reasonable request.

Ethics approval and consent to participate: not applicable.

Consent for publication: not applicable.

Competing interests: the authors declare no competing interests.

\section{References}

1. Albuquerque ELD, Lima JKA, Souza FHO et al (2013) Insecticidal and repellence activity of the essential oil of Pogostemon cablin against urban ants species. Acta Trop 127:181-186. https://doi.org/10.1016/j.actatropica.2013.04.011

2. Athanassiou CG, Kavallieratos NG, Benelli G et al (2018) Nanoparticles for pest control: current status and future perspectives. J Pest Sci 91:1-15. https://doi.org/10.1007/s10340-017-0898-0

3. Baker PS, Barrera JF, Rivas A (1992) Life-History studies of the coffee berry borer (Hypothenemus hampei, Scolytidae) on coffee trees in Southern Mexico. J App Ecol 29:656-662. https://doi.org/10.2307/2404473

4. Bates D, Maechler M, Bolker B, Walker S (2015) Fitting linear mixed-effects models using Ime4. J Stat Softw 6:1-48. https://doi.org/10.18637/jss.v067.i01

5. Bolzonella C, Lucchetta M, Teo G et al (2019) Is there a way to rate insecticides that is less detrimental to human and environmental health? Glob Ecol Conserv 20:e00699. https://doi.org/10.1016/j.gecco.2019.e00699

6. Carneiro LS, Martínez LC, Gonçalves WG et al (2020) The fungicide iprodione affects midgut cells of non-target honey bee Apis mellifera workers. Ecotoxicol Environ Saf 189:109991. https://doi.org/10.1016/j.ecoenv.2019.109991

7. Cordeiro EMG, Corrêa AS, Venzon M, Guedes RNC (2010) Insecticide survival and behavioral avoidance in the lacewings Chrysoperla externa and Ceraeochrysa cubana. Chemosphere 81:13521357. https://doi.org/10.1016/j.chemosphere.2010.08.021

8. Cruz-Landim C, Serrão JE, Silva de Moraes RLM (1996) Cytoplasmic protrusions from digestive cells of bees. Cytobios 88:95-104

9. da Silva Cruz A, da Silva-Zacarin ECM, Bueno OC, Malaspina O (2010) Morphological alterations induced by boric acid and fipronil in the midgut of worker honeybee (Apis mellifera L.) larvae: 
Morphological alterations in the midgut of $A$. mellifera. Cell Biol Toxicol 26:165-176. https://doi.org/10.1007/s10565-009-9126-x

10. de Oliveira BMS, Melo CR, Santos ACC et al (2019) Essential oils from Varronia curassavica (Cordiaceae) accessions and their compounds (E)-caryophyllene and a-humulene as an alternative to control Dorymyrmex thoracius (Formicidae: Dolichoderinae). Environ Sci Pollut Res 26:6602-6612. https://doi.org/10.1007/s11356-018-4044-1

11. Farder-Gomes CF, Fernandes KM, Bernardes RC et al (2021a) Acute exposure to fipronil induces oxidative stress, apoptosis and impairs epithelial homeostasis in the midgut of the stingless bee Partamona helleri Friese (Hymenoptera: Apidae). Sci Total Environ 774:145679. https://doi.org/10.1016/j.scitotenv.2021.145679

12. Farder-Gomes CF, Fernandes KM, Bernardes RC et al (2021b) Harmful effects of fipronil exposure on the behavior and brain of the stingless bee Partamona helleri Friese (Hymenoptera: Meliponini). Sci Total Environ 794:148678. https://doi.org/10.1016/j.scitotenv.2021.148678

13. Farder-Gomes CF, Saravanan M, Martínez LC et al (2021c) Azadirachtin-based biopesticide affects the respiration and digestion in Anticarsia gemmatalis caterpillars. Toxin Rev online. https://doi.org/10.1080/15569543.2021.1892764

14. Fiaz M, Martínez LC, Costa M da et al (2018) Squamocin induce histological and ultrastructural changes in the midgut cells of Anticarsia gemmatalis (Lepidoptera: Noctuidae). Ecotoxicol Environ Saf 156:1-8. https://doi.org/10.1016/j.ecoenv.2018.02.080

15. González JOW, Stefanazzi N, Murray AP et al (2015) Novel nanoinsecticides based on essential oils to control the German cockroach. J Pest Sci 88:393-404. https://doi.org/10.1007/s10340-014-06071

16. Hashem AS, Awadalla SS, Zayed GM et al (2018) Pimpinella anisum essential oil nanoemulsions against Tribolium castaneum-insecticidal activity and mode of action. Environ Sci Pollut Res 25:18802-18812. https://doi.org/10.1007/s11356-018-2068-1

17. Hlina BL (2020) ecotox: Analysis of Ecotoxicology. Version 1.4.2. R package. URL https://cran.rproject.org/web/packages/ecotox/index.html

18. Infante F (2018) Pest Management Strategies Against the Coffee Berry Borer (Coleoptera: Curculionidae: Scolytinae). J Agric Food Chem 66:5275-5280. https://doi.org/10.1021/acs.jafc.7b04875

19. Isman MB (2020) Botanical insecticides in the twenty-first century-fulfilling their promise? Annu Rev Entomol 65:233-249. https://doi.org/10.1146/annurev-ento-011019-025010

20. Kogan A, Garti N (2006) Emulsions as transdermal drug delivery vehicles. Adv Colloid Interface Sci 123-126:369-385. https://doi.org/10.1016/j.cis.2006.05.014

21. Lenth R (2020) emmeans: Estimated Marginal Means, aka Least-Squares Means. Version 1.4.6. R package. URL https://CRAN.R-project.org/package=emmeans

22. Liu C-H, Chang F-Y, Hung D-K (2011) Terpene emulsions for transdermal curcumin delivery: Effects of terpenes and cosurfactants. Colloids Surf B Biointerfaces 82:63-70. 
https://doi.org/10.1016/j.colsurfb.2010.08.018

23. Lüdecke $D$, Ben-Shachar M, Patil I et al (2021) performance: an R package for assessment, comparison and testing of statistical models. J Open Source Softw 6:3139. https://doi.org/10.21105/joss.03139

24. Melo CR, Oliveira BMS, Santos ACC et al (2020) Synergistic effect of aromatic plant essential oils on the ant Acromyrmex balzani (Hymenoptera: Formicidae) and antifungal activity on its symbiotic fungus Leucoagaricus gongylophorus (Agaricales: Agaricaceae). Environ Sci Pollut Res 27:1730317313. https://doi.org/10.1007/s11356-020-08170-z

25. Menezes RG, Qadir TF, Moin A et al (2017) Endosulfan poisoning: An overview. J Forensic Leg Med 51:27-33. https://doi.org/10.1016/j.jflm.2017.07.008

26. Noguchi M, Hirata N, Tanaka T et al (2020) Autophagy as a modulator of cell death machinery. Cell Death Dis 11:517. https://doi.org/10.1038/s41419-020-2724-5

27. Oliveira AP, Santana AS, Santana EDR et al (2017) Nanoformulation prototype of the essential oil of Lippia sidoides and thymol to population management of Sitophilus zeamais (Coleoptera: Curculionidae). Ind Crops Prod 107:198-205. https://doi.org/10.1016/j.indcrop.2017.05.046

28. Park CG, Jang M, Yoon KA, Kim J (2016) Insecticidal and acetylcholinesterase inhibitory activities of Lamiaceae plant essential oils and their major components against Drosophila suzukii (Diptera: Drosophilidae). Ind Crops Prod 89:507-513. https://doi.org/10.1016/j.indcrop.2016.06.008

29. Pavoni L, Perinelli DR, Bonacucina G et al (2020) An Overview of micro- and nanoemulsions as vehicles for essential oils: formulation, preparation and stability. Nanomaterials 10:135. https://doi.org/10.3390/nano10010135

30. Plata-Rueda A, Martínez LC, Costa NCR et al (2019) Chlorantraniliprole-mediated effects on survival, walking abilities, and respiration in the coffee berry borer, Hypothenemus hampei. Ecotoxicol Environ Saf 172:53-58. https://doi.org/10.1016/j.ecoenv.2019.01.063

31. Rattan RS (2010) Mechanism of action of insecticidal secondary metabolites of plant origin. Crop Prot 29:913-920. https://doi.org/10.1016/j.cropro.2010.05.008

32. Regnault-Roger C, Vincent C, Arnason JT (2012) Essential oils in insect control: low-risk products in a high-stakes world. Annu Rev Entomol 57:405-424. https://doi.org/10.1146/annurev-ento-120710100554

33. Reyes EIM, Farias ES, Silva EMP et al (2019) Eucalyptus resinifera essential oils have fumigant and repellent action against Hypothenemus hampei. Crop Prot 116:49-55. https://doi.org/10.1016/j.cropro.2018.09.018

34. Rocha AG, Oliveira BMS, Melo CR et al (2018) Lethal effect and behavioral responses of leaf-cutting ants to essential oil of Pogostemon cablin (Lamiaceae) and its nanoformulation. Neotrop Entomol 47:769-779. https://doi.org/10.1007/s13744-018-0615-6

35. Santos ACC, Cristaldo PF, Araújo APA et al (2018) Apis mellifera (Insecta: Hymenoptera) in the target of neonicotinoids: A one-way ticket? Bioinsecticides can be an alternative. Ecotoxicol Environ Saf 163:28-36. https://doi.org/10.1016/j.ecoenv.2018.07.048 
36. Santos Junior VC, Martínez LC, Plata-Rueda A et al (2020) Histopathological and cytotoxic changes induced by spinosad on midgut cells of the non-target predator Podisus nigrispinus Dallas (Heteroptera: Pentatomidae). Chemosphere 238:124585.

https://doi.org/10.1016/j.chemosphere.2019.124585

37. Shahzad K, Manzoor F (2021) Nanoformulations and their mode of action in insects: a review of biological interactions. Drug Chem Toxicol 44:1-11.

https://doi.org/10.1080/01480545.2018.1525393

38. Shi B, Wang Z, Wen H (2017) Research on the strengths of electrostatic and van der Waals interactions in ionic liquids. J Mol Liq 241:486-488. https://doi.org/10.1016/j.molliq.2017.06.057

39. Tak J-H, Isman MB (2015) Enhanced cuticular penetration as the mechanism for synergy of insecticidal constituents of rosemary essential oil in Trichoplusia ni. Sci Rep 5:12690. https://doi.org/10.1038/srep12690

40. Tak J-H, Jovel E, Isman MB (2016) Comparative and synergistic activity of Rosmarinus officinalis L. essential oil constituents against the larvae and an ovarian cell line of the cabbage looper, Trichoplusia ni (Lepidoptera: Noctuidae). Pest Manag Sci 72:474-480. https://doi.org/10.1002/ps.4010

41. Terra WR, Costa RH, Ferreira C (2006) Plasma membranes from insect midgut cells. An Acad Bras Ciênc 78:255-269. https://doi.org/10.1590/S0001-37652006000200007

42. Therneau T (2021) survival: A Package for Survival Analysis in R. Version 3.2-11. R package. URL https://CRAN.R-project.org/package=survival

43. Turchen LM, Cosme-Júnior L, Guedes RNC (2020) Plant-derived insecticides under meta-analyses: status, biases, and knowledge gaps. Insects 11:532. https://doi.org/10.3390/insects 11080532

44. van Beek TA, Joulain D (2018) The essential oil of patchouli, Pogostemon cablin: A review. Flavour Fragr J 33:6-51. https://doi.org/10.1002/ffj.3418

45. Vega FE, Franqui RA, Benavides $P$ (2002) The presence of the coffee berry borer, Hypothenemus hampei, in Puerto Rico: fact or fiction? J Insect Sci 2:1-3. https://doi.org/10.1673/031.002.1301

46. Vega FE, Infante F, Johnson AJ (2015) The genus Hypothenemus, with emphasis on H. hampei, the coffee berry borer. Bark Beetles. Elsevier, pp 427-494

47. Wickham H (2016) ggplot2: Elegant Graphics for Data Analysis. Springer-Verlag, New York 48. Wickham H (2016) ggplot2: Elegant Graphics for Data Analysis. Springer-Verlag, New York

\section{Figures}




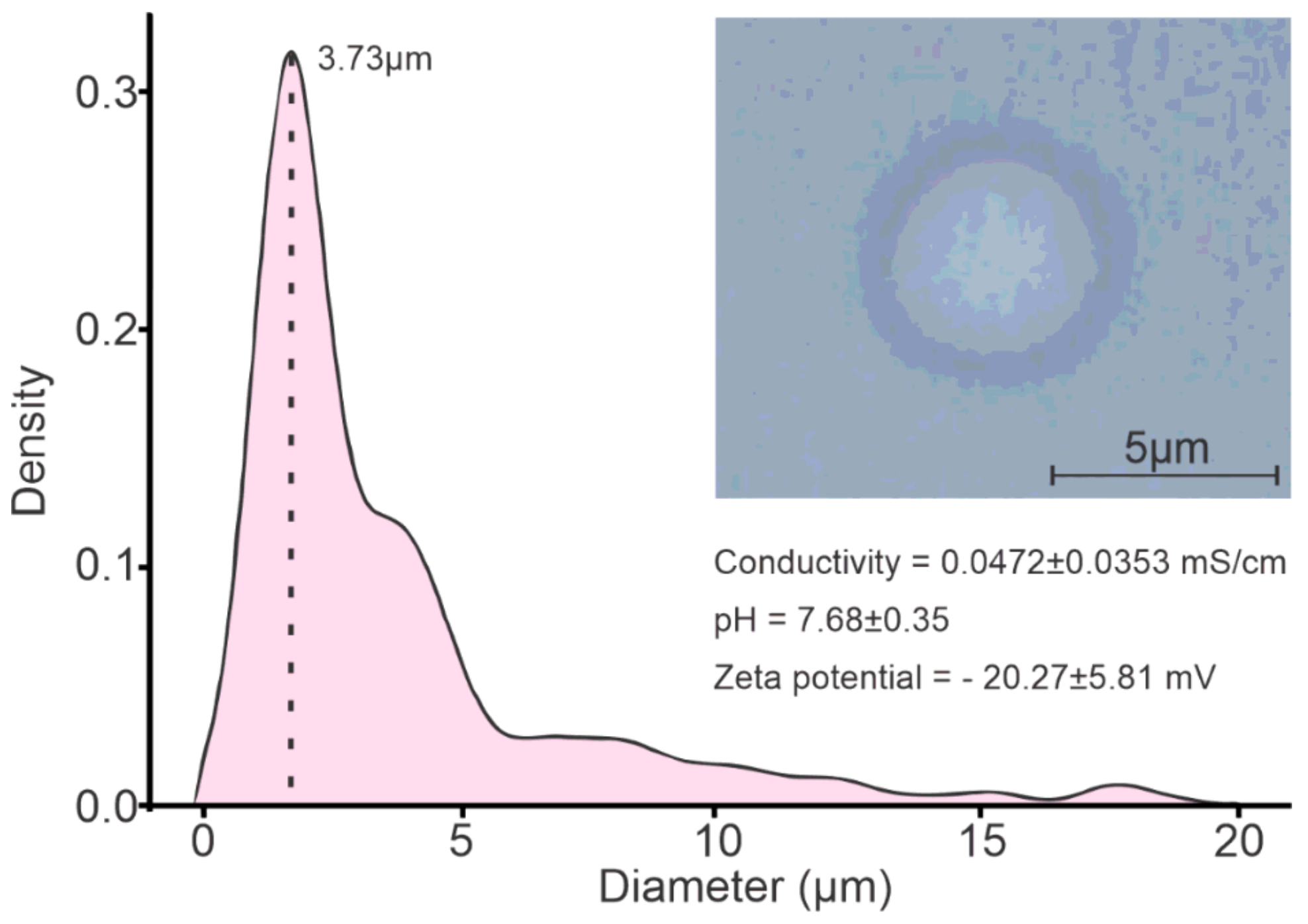

Figure 1

Image of emulsion containing $18 \%$ of Pogostemon cablin essential oil (top right) and its conductivity, particle size $(n=250), p H$, and zeta potential parameters $(n=3)$. The image was obtained by light microscopy at 100x magnification. The dotted line indicates the mean micro-particle size. 


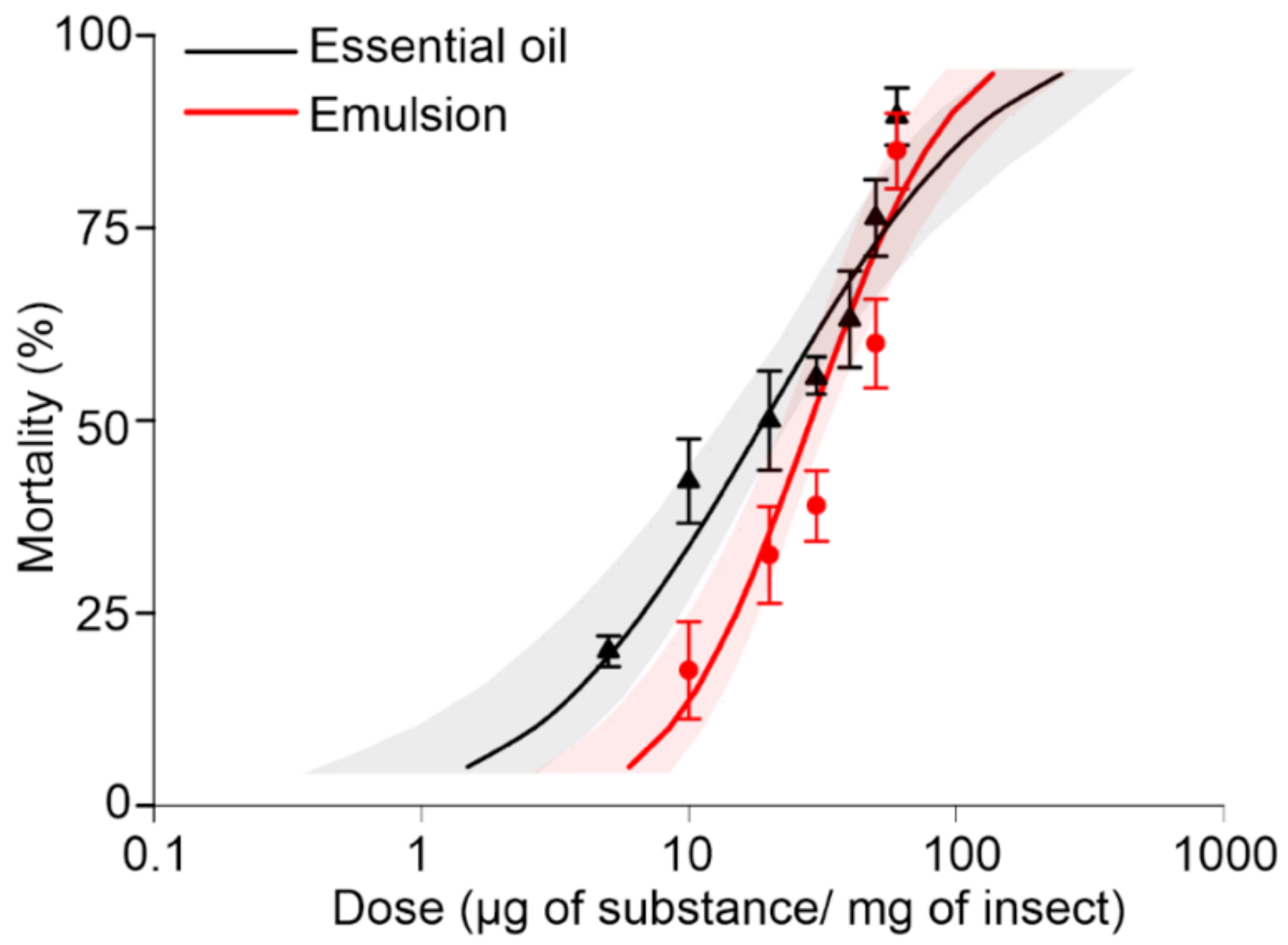

Figure 2

Toxicity of essential oil (EO) of Pogostemon cablin and an EO-based emulsion (18\% of P. cablin EO) against female adults of coffee berry borer (Hypothenemus hampei). Lethal doses (log scale) were estimated based on dose-response bioassays using Probit analysis (EO: $\chi^{2}=7.35$, $d f=5 ; P=0.20$; emulsion: $\chi^{2}=2.66, d f=3 ; P=0.45$ ). Shaded areas represent $95 \%$ confidence intervals. Triangles (black) and circles (red) indicate the mean \pm standard deviation from the mortalities observed in the bioassays. 


\section{Treatment + Control + Essential Oil + Emulsion}

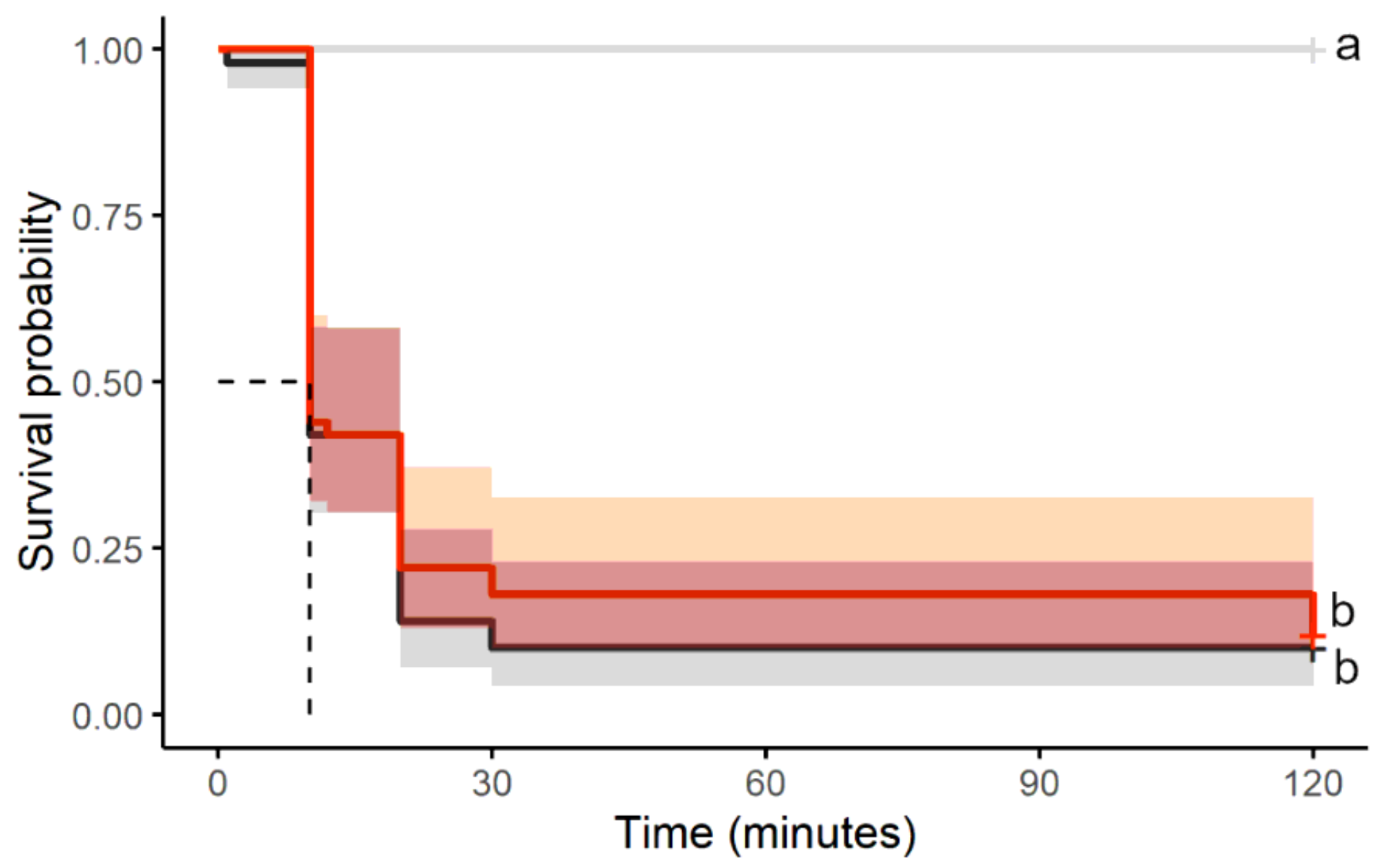

Figure 3

Survival probability curves of female adults of coffee berry borer (Hypothenemus hampei) exposed to Pogostemon cablin essential oil (EO) and an EO-based emulsion (18\% of $P$. cablin EO) at their respective lethal dose to kill $90 \%$ of the population. Shaded areas represent $95 \%$ confidence intervals. Different lower case letters indicate significant differences among treatments (Kaplan-Meier method, Log-rank test, and Bonferroni correction: $\left.\chi^{2}=103, d f=2 ; P<0.0001\right)$; dotted line indicates the $L T_{50}$. 


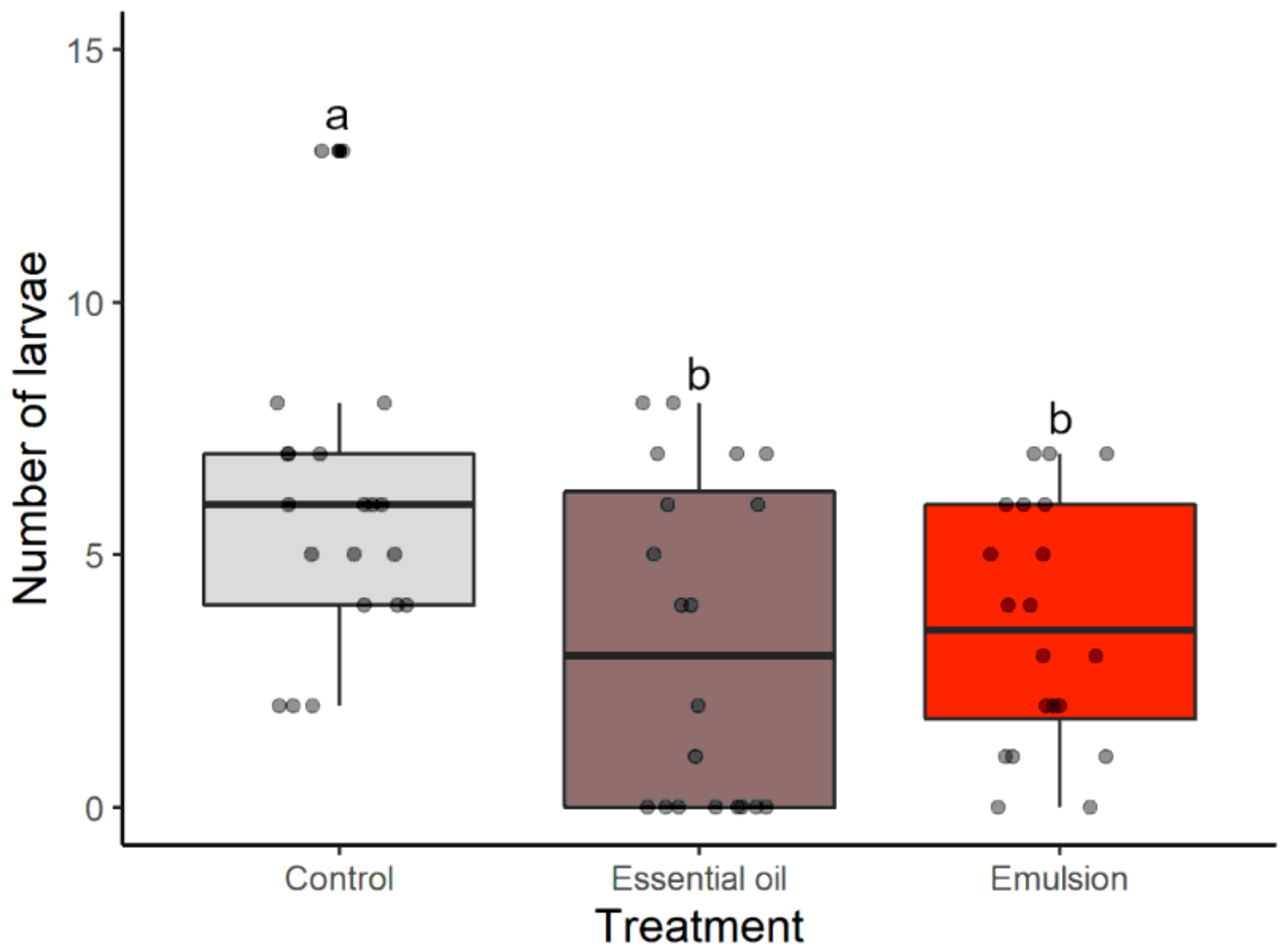

Figure 4

Number of larvae from female adults of coffee berry borer (Hypothenemus hampei) 30 days after topical exposure to Pogostemon cablin essential oil (EO) and an EO-based emulsion (18\% of $P$. cablin EO) at their respective lethal dose to kill $25 \%$ of the population. Box plots indicate the range of data dispersion (first and third quartiles and extreme values), median (solid line), and data from each replicate (points). Different lower case letters indicate significant differences among treatments (GLM Quasi-Poisson distribution; $F=4.73, d f=2,57 ; P=0.01$ ). 


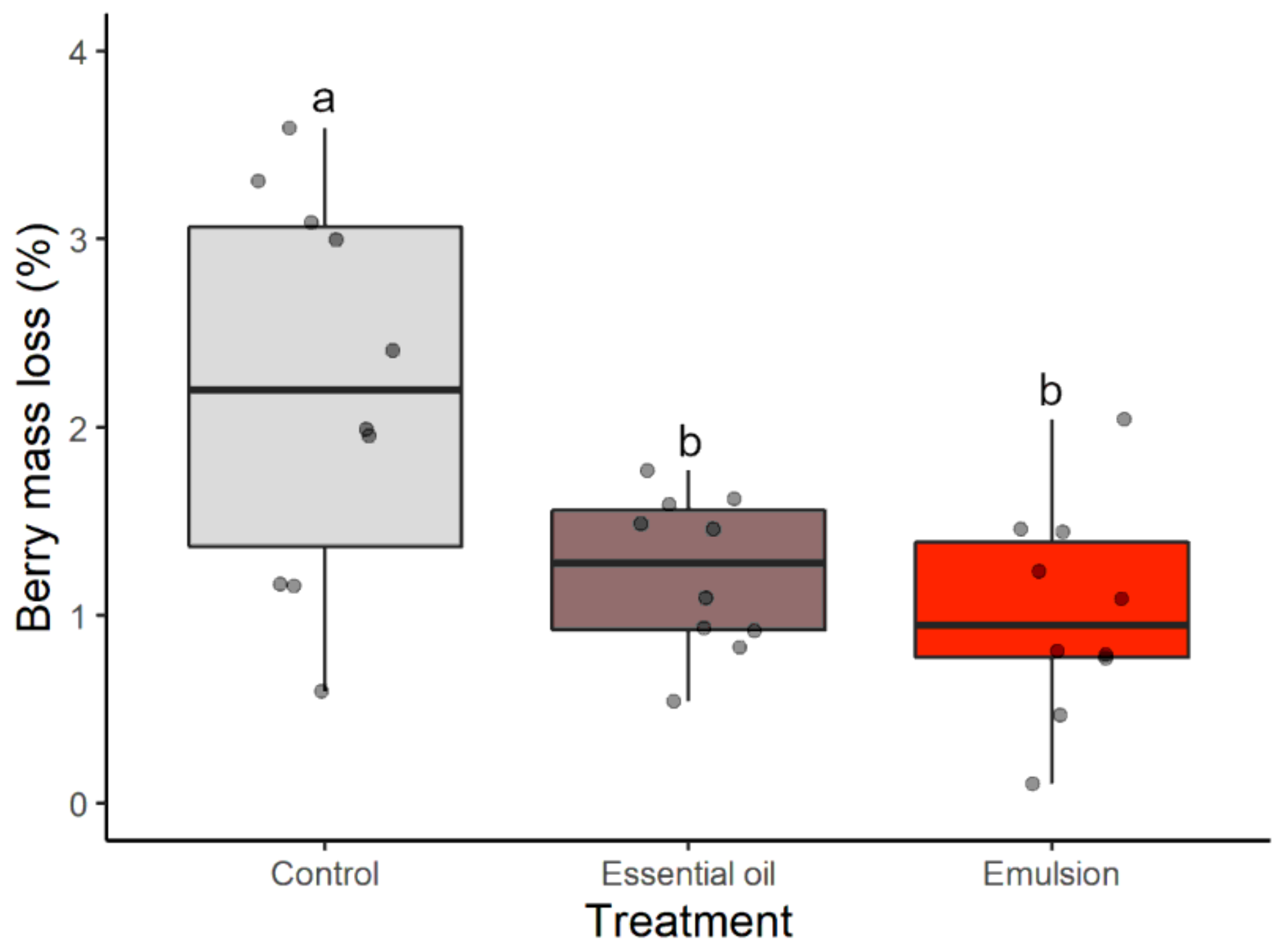

Figure 5

Berry mass loss (\%) of coffee berries 72 hours after exposure to female adults of coffee berry borer (Hypothenemus hampel) topically treated with Pogostemon cablin essential oil (EO) and an EO-based emulsion ( $18 \%$ of $P$. cablin EO) at their respective lethal dose to kill $25 \%$ of the population. Box plots indicate the range of data dispersion (first and third quartiles and extreme values), median (solid line), and data from each replicate (points). Different lower case letters indicate significant differences among treatments (GLM Quasi-Binomial distribution: $F=8.74, d f=2,27 ; P=0.001$ ). 
(a) Displacement

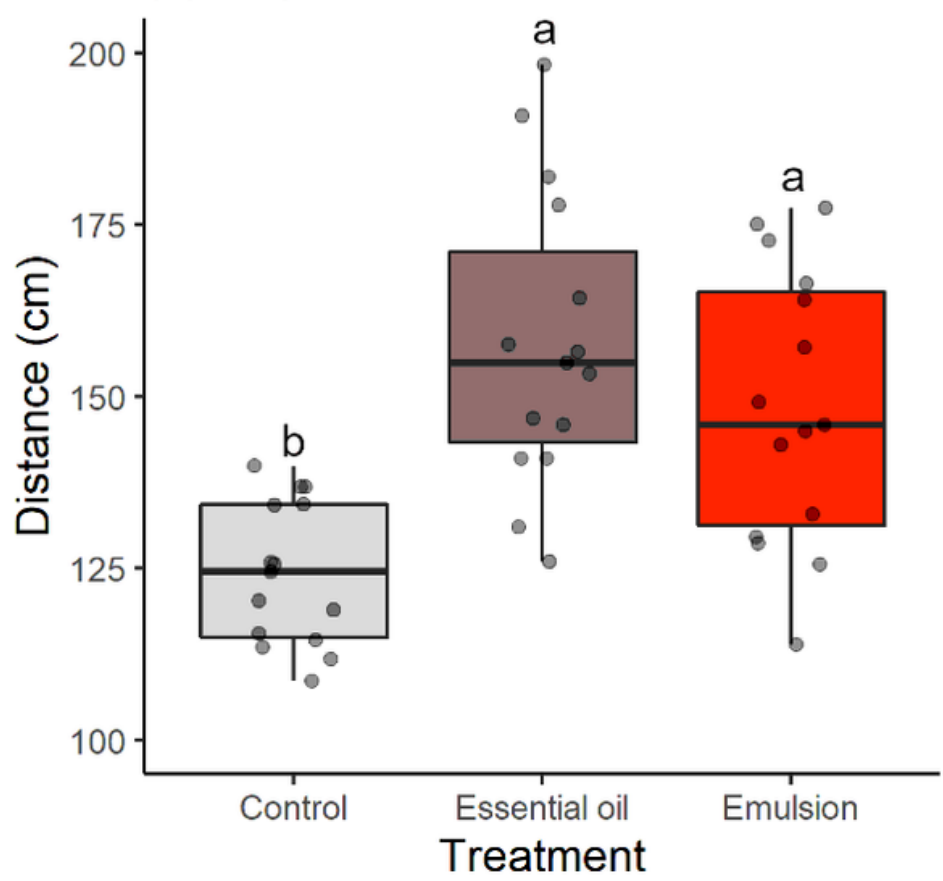

(b) Walking speed

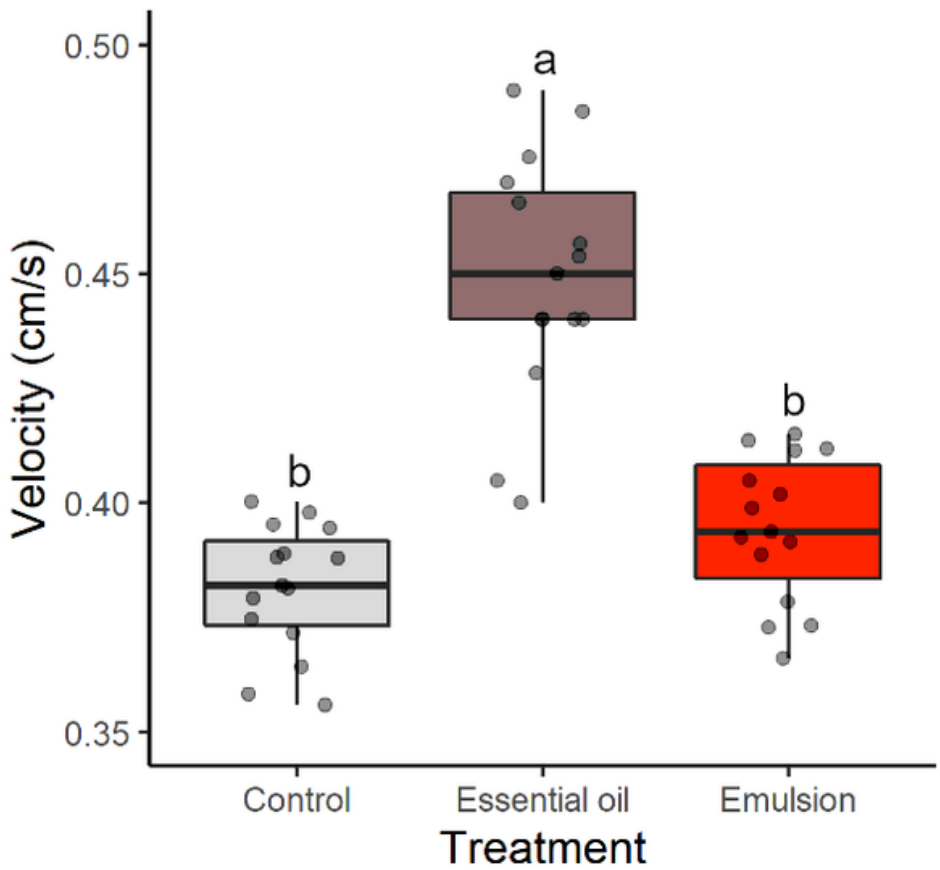

\section{Figure 6}

Mobility [(a) displacement and (b) walking speed] of female adults of coffee berry borer (Hypothenemus hampei) 72 hours after topical exposure to Pogostemon cablin essential oil (EO) and an EO-based emulsion ( $18 \%$ of $P$. cablin EO) at their respective lethal dose to kill $25 \%$ of the population. Box plots indicate the range of data dispersion (first and third quartiles and extreme values), median (solid line), and data from each replicate (points). Different lower case letters indicate significance.

\section{Figure 7}

Light micrographs of the midgut of Hypothenemus hampei. (A-B) Epithelium of the control group with the digestive cells showing rounded nuclei with the predominance of decondensed chromatin $(N)$ and welldeveloped brush border (Bb). Lumen ( $(\mathrm{L})$. (C-D) Insects exposed to Pogostemon cablin essential oil after $72 \mathrm{~h}$ showing digestive with vacuoles $(\mathrm{V})$, disorganized brush border $(\mathrm{Bb})$, and cell fragments (arrowheads) released to the lumen (L). (E-F) Insects exposed to emulsion (18\% of EO) after $72 \mathrm{~h}$ showed an intensification of the vacuolization $(\mathrm{V})$ and disorganization of the brush border $(\mathrm{Bb})$. Note the nuclei with condensed chromatin $(\mathrm{N})$ and cell fragments (arrowheads) released to the lumen $(\mathrm{L})$. Bars $\mathrm{A}, \mathrm{C}$ and $\mathrm{E}$ $=40 \mu \mathrm{m} ; \mathrm{B}, \mathrm{D}$ and $\mathrm{F}=20 \mu \mathrm{m}$.

\section{Figure 8}


Light micrographs of the brain and ovaries of Hypothenemus hampei of the control group (A-B) and exposed to the Pogostemon cablin essential oil (C-D) or emulsion (E-F) after $72 \mathrm{~h}$. Kenyon cells (Kc), neuropil of the mushroom bodies ( $\mathrm{Ne}$ ), and antennal lobe (Al). Tropharium (Tr), oocyte (Oc), germinal vesicle (arrowhead), follicular cells ( $F c)$, and peritoneal sheath (Ps). Bars $=40 \mu \mathrm{m}$.

\section{Supplementary Files}

This is a list of supplementary files associated with this preprint. Click to download.

- supplementalinformation.docx 